\title{
The Effects of the MTHFR 677C>T (rs1801133) Genetic Variant on Susceptibility and Disability in Multiple Sclerosis Patients are Mediated by Homocysteine but Not Folate Levels
}

\author{
Claudia Mara Ribeiro \\ State University of Londrina: Universidade Estadual de Londrina \\ Sayonara Rangel Oliveira \\ State University of Londrina: Universidade Estadual de Londrina \\ Tamires Flauzino \\ State University of Londrina: Universidade Estadual de Londrina \\ Daniela Frizon Alfieri \\ Universidade Estadual de Londrina \\ Andrea Name Colado Simão \\ State University of Londrina: Universidade Estadual de Londrina \\ Marcell Alysson Batisti Lozovoy \\ State University of Londrina: Universidade Estadual de Londrina \\ Michael Maes \\ Deakin University \\ Edna Maria Vissoci Reiche ( $\nabla$ reiche@sercomtel.com.br)
}

Universidade Estadual de Londrina Centro de Ciencias da Saude https://orcid.org/0000-0001-6507-2839

\section{Research Article}

Keywords: multiple sclerosis, methylenetetrahydrofolate reductase, MTHFR, homocysteine, folate, inflammation

Posted Date: October 4th, 2021

DOI: https://doi.org/10.21203/rs.3.rs-947647/v1

License: (c) (i) This work is licensed under a Creative Commons Attribution 4.0 International License. Read Full License 


\section{Abstract}

We investigated whether the MTHFR 677C>T (rs1801133) variant and plasma homocysteine and folate are associated with multiple sclerosis (MS), disability, disability progression, and inflammatory biomarkers. We included 163 MS patients categorized using the Expanded Disability Status Scale (EDSS) as mild (EDSS $<3$ ) and moderate/high (EDSS $\geq 3$ ) disability, and 226 healthy controls. Disability progression was evaluated using Multiple Sclerosis Severity Score (MSSS) and the MTHFR 677C>T was genotyped using real time polymerase chain reaction. The levels of some inflammatory biomarkers and inflammatory activity index (IAI) were determined. There was no association between the MTHFR 677 C $>$ T genotypes and MS, EDSS, and MSSS ( $p>0.05$ ). Plasma folate and homocysteine were higher and adiponectin was lower in MS patients than controls ( $p<0.001)$. Moreover, $21.8 \%$ of the EDSS variance was explained by age, IAI and C-reactive protein (CRP) (all positively associated); $10.9 \%$ of the MSSS variance was predicted by IAI and CRP (both positively) and vitamin D3 (negatively), whereas $54.4 \%$ of the MS-EDSS-MSSS score was explained by the regression on age, IAl, homocysteine, folate, and CRP (all positively) and adiponectin, body mass index, and vitamin D3 (all negatively), female sex and the MTHFR 677 TT genotype. In patients and controls, $16.6 \%$ of the variance in the homocysteine was explained by the MTHFR 677 TT genotype and age (both positively), folate (negatively) and male sex. In conclusion, the MTHFR 677C>T variant was not directly associated with MS, disability, and disability progression; however, the TT genotype showed indirect effects on MS susceptibility and disability mediated by homocysteine.

\section{Introduction}

Multiple sclerosis (MS) is a chronic inflammatory disease characterized by the demyelination of the central nervous system (CNS), often followed by progressive and irreversible neurological dysfunction. The etiology of MS has been not yet well defined but interactions between genetic and environmental factors have been recognized to contribute to the autoimmune inflammatory process [1]. Deficiency of vitamin D, folate and vitamin B12 as well as increased levels of homocysteine are some of the important environmental factors associated with the pathophysiology of MS [28].

High levels of homocysteine, named as hyperhomocysteinemia, may have toxic effects on both neurons and blood vessels, including endothelial dysfunction and oxidative damage, thus contributing to neurodegenerative diseases, such as MS [9-12]. Homocysteine is considered an inflammatory biomarker and its plasma levels is influenced by a diversity of physiologic and acquired factors and by interactions between such factors, including age, sex, drugs, and MTHFR genetic variants [13-15]. The MTHFR gene encodes methylenetetrahydrofolate reductase (MTHFR), a key enzyme-regulating folate and homocysteine metabolism [16]. MTHFR catalyzes the reduction of 5,10-methylenetetrahydrofolate to 5methylenetetrahydrofolate, which is the main form of folate in plasma and a carbon donor for the remethylation of homocysteine to methionine [17]. Several genetic variants are identified in the MTHFR of which, the most studied and clinically important is the 677C>T (rs1801133) located in exon 4, which results in substitution of alanine by valine at position 222 (p.Ala222Val or A222V) of the protein [18, 19]. Racial-ethnic differences in distribution of the MTHFR $677 \mathrm{C}>\mathrm{T}$ variant have been described $[20,21]$ and association between the MTHFR $677 \mathrm{C}>\mathrm{T}$ variant and high levels of homocysteine has been reported [22-26]. Individuals carrying the TT genotype have a reduced activity of the MTHFR enzyme and increased plasma levels of homocysteine [27, 28].

Previous studies have reported increased plasma levels of homocysteine in patients with MS compared to healthy subjects [8, 29, 30]. We previously demonstrated that homocysteine levels are higher in MS patients than in controls, as well as higher among those with moderate/high disability than those with mild disability [8]. Discrepancies on the correlations between MS and plasma levels of homocysteine, vitamin B12, and folate have been reported. While some studies showed higher levels of homocysteine and lower levels of vitamin B12 and folate in MS patients compared to controls [30,31], others reported no differences between patients with MS and controls in the levels of homocysteine [32-34], vitamin B12 or folate [32].

Considering that the relationship between MTHFR $677 \mathrm{C}>\mathrm{T}$, homocysteine, and folate in MS patients remains unclear and that their role were not extensively explored in the clinical course of the disease, the aim of this study was to verify whether the MTHFR 677C>T (rs1801133) variant and plasma levels of homocysteine and folate are associated with MS susceptibility, disability, disability progression, and inflammatory biomarkers.

\section{Material And Methods}

\section{Subjects}

The case-control study included 163 MS patients, adults and both sexes, consecutively recruited from the Demyelinating Diseases Outpatient of the State University of Londrina, Londrina, Paraná, South Brazil, one of the specialized reference centers for the diagnosis and treatment of MS at the Parana State, Southern Brazil. The MS diagnosis was established according to the McDonald criteria [35]. The patients were clinically evaluated for disability using the Expanded Disability Status Scale (EDSS) [36]. Based on their EDSS scores, the patients were divided into two groups: EDSS < 3 (mild disability) and EDSS $\geq 3$ (moderate/high disability). Disability progression was evaluated using the Multiple Sclerosis Severity Score (MSSS), as proposed elsewhere [37] and score $\geq 5.0$ denoted higher than the average speed of disability accumulation [38]. A single MS severity index was entered as a latent vector extracted from the MS diagnosis, EDSS and MSSS scores, named as MS-EDSS-MSSS. 
All MS patients were in the remission clinical phase, defined as the period of recovery with no relapse episodes within the last three months prior to the time of enrollment in the study. As controls, 226 healthy individuals (HC) were selected among blood donors of the Regional Blood Bank of Londrina, from the same geographic region of the MS patients. None of the participants of the study presented clinical symptoms or laboratory biomarkers of heart, thyroid, kidney, hepatic, gastrointestinal, or oncologic diseases, as well as other inflammatory and autoimmune diseases.

Demographic, epidemiological and anthropometric data (for MS patients and HC), as well as clinical history and the use of therapy for MS before the inclusion in this study (for MS patients) were obtained using a standard questionnaire at the admission of the individuals. Body mass index (BMI) was calculated as weight (kg) divided by height $(\mathrm{m})$ squared and the ethnicity was classified according to individual's self-perception of skin color as Caucasian and non-Caucasian [39]. Other data were obtained including waist circumference, current smoking, systemic arterial hypertension (SAH), metabolic syndrome (MetS) and type 2 diabetes mellitus (T2DM). Systolic blood pressure (SBP) and diastolic blood pressure (DBP) were measured twice and the mean of these two measurements was used in the analysis. Moreover, use of antihypertensive medication was an indication of SAH [40]. T2DM was defined as a fasting serum glucose $\geq 126 \mathrm{mg} / \mathrm{dL}$ and/or use of hypoglycemic medication [41].

The protocol was approved by the Institutional Research Ethics Committees of University of Londrina, Paraná, Brazil (CAAE: 22290913.9.0000.5231) and all of the individuals invited were informed in detail about the research and gave written informed consent.

Blood samples

Peripheral blood samples were drawn after $12 \mathrm{~h}$ of fasting using vacuo system tubes (Vacutainer System, Becton-Dickinson, New Jersey, U.S) with and without ethylenediamine tetra-acetic acid (EDTA) as anticoagulant. The specimens were centrifuged at 2,500 rpm for 10 minutes within 2 hours after sampling. The buffy-coat, plasma and sera were frozen at $-80^{\circ} \mathrm{C}$ until analysis.

\section{MTHFR 677C>G Genetic Variant Genotyping}

Genomic DNA was extracted from the buffy-coat of peripheral blood cells using a resin column procedure (Biopur, Biometrix Diagnostika, Curitiba, Brazil) following the manufacturer's instructions. DNA concentration was measured using a spectrophotometer at $260 \mathrm{~nm}$ (NanoDrop $2000 \mathrm{c}^{\mathrm{TM}}$, ThermoScientific, Waltman, MA, USA) and the DNA purity was assessed by 260/280 nm ratio. The MTHFR 677C>T (rs1801133) variant was determined using TaqMan® allelic discrimination validated assay on real-time polymerase chain reaction (qPCR) system (StepOne, Applied Biosystems by Life Technologies, Carlsbad, CA, USA) with the allele-specific fluorogenic oligonucleotide probe (C__1202883_20). The reaction was performed using $5 \mathrm{ng}$ of genomic DNA, $0.25 \mu \mathrm{L}$ TaqMan SNP Genotyping Assay 40x (Applied Biosystems, Foster City, CA, USA) containing two sequence-specific primers and two allele-specific TaqMan ${ }^{\circledR}$ MGB probes with a reporter dye at its $5^{\prime}$ end $\left(\mathrm{VIC}^{\circledR}\right.$ or FAM $\left.{ }^{\mathrm{TM}}\right), 5 \mu \mathrm{L}$ TaqMan Universal Genotyping Master Mix (Applied Biosystems, Foster City, CA, USA). Negative and positive controls were also included in the reactions.

\section{Inflammatory Biomarkers}

Plasma levels of homocysteine, folate, and vitamin D3 (measured as 1,25 dihydroxyvitamin D) were determined by chemiluminescence microparticle immunoassay (CMIA, Architect, Abbott Laboratory, Abbott Park, IL, USA). The reference values for homocysteine are up to 9.0 umol/L (male) and up to $7.0 \mu \mathrm{mol} / \mathrm{L}$ (female); for the folate, the values are $3.1-20.5 \mathrm{ng} / \mathrm{mL}$, as recommended by the manufacturers. Uric acid plasma levels were evaluated using a biochemical auto-analyzer (Dimension Dade AR Dade Behring, Deerfield, IL, USA). C-reactive protein (CRP) determined with high sensitivity assay (hsCRP) using turbidimetry (Architect C8000, Abbott Laboratory, Abbott Park, IL, USA), and plasma levels of interleukin (IL)-2, IL-4, IL-6, IL-10, interferon (IFN)-y, tumor necrosis factor (TNF)-a, soluble TNF-a receptor (sTNFR)1 and sTNFR2 were determined using immunofluorimetric method with microspheres multiplex immunoassay (Novex Life Technologies, Frederick, USA) for Luminex platform in MAGPIX® instrument (Luminex Corp., TX, USA).

Two new composed inflammatory scores were proposed: the first, namely as immune activation index (IAI), was entered as a latent vector extracted from macrophage M1 cytokines (IL-6 and TNF-a) + T helper (Th)1 cytokines (IL-2 and IFN- $y$ ) + Th17 cytokines (IL-6 and IL-17), and Th2+T regulatory (Treg) cytokines (IL-4 and IL-10); the second, namely as TNF-a and its receptors, was entered as a latent vector extracted from TNF-a + sTNFR1+sTNFR2.

\section{Statistical analysis}

Analysis of variance (ANOVA) was employed to assess differences in continuous variables between study groups, and analysis of contingency tables (chi-square test) to check associations between classifications. Univariate general linear models (GLM) analysis was performed to assess the differences in biomarkers between three subgroups ( $\mathrm{HC}$ and two patient classes). Multiple pair-wise differences were assessed with protected Least Significant Difference (LSD) tests. Automatic multiple regression analysis was employed to predict dependent variables (e.g., the EDSS or MSSS scores) using explanatory variables (e.g., biomarkers, age, sex, and BMI). An automatic stepwise (step-up) method was used with a p-to-enter of 0.05 and p-to-remove 0.06 while checking $\mathrm{R}^{2}$ changes, homoscedasticity (using White and modified Breusch-Pagan tests for homoscedasticity), multicollinearity (using tolerance and VIF), and multivariate normality (Cook's distance and leverage). Results of multiple comparisons were pcorrected for false discovery rate (FDR) [42]. Automatic binary logistic regression analysis was conducted with MS or MS subgroups as dependent variables and the biomarkers as input variables. Odds ratios (OR) with 95\% confidence intervals $(\mathrm{Cl})$ and the accuracy of classification (with sensitivity and specificity) were computed and Nagelkerke's peudo- $\mathrm{R}^{2}$ values were used as effect size measurement. The results of these regression

Page $3 / 19$ 
analyses were always bootstrapped using 5.000 bootstrap samples and the latter results are shown if the results are not concordant. All tests are two-tailed and a p-value of 0.05 was employed to determine statistical significance. Statistical analyses were carried out using IBM SPSS Windows version 25, 2017.

Partial Least Squares (SmartPLS) analysis [43] was used to measure the multi-step multiple mediation associations between biomarkers (input variables) and the MS-severity index. The latter was entered as a latent vector extracted from the EDSS and MSSS scores and the diagnosis MS. All biomarkers were entered as single indicators except IAI, which was entered as a latent vector extracted from different immune profiles. Both latent vectors were entered as reflective models. Consequently, complete PLS path analysis using 5.000 bootstrap samples was performed only when the outer and inner models complied with pre-specified quality data: a) all outer model loadings on both latent vectors are $>0.7$ at $p<0.001$ and all latent vectors show good construct validity as indicated by Cronbach's alpha ( $>0.7)$, composite reliability $(>0.7)$, rho A ( $>0.8)$, and average variance extracted (AVE) > 0.5; b) the overall fit of the model is adequate as indicated by Standardized Root Mean Squared Residual (SRMR) < 0.08; and c) Confirmatory Tetrad analysis indicates that both latent vectors models are not mis-specified as reflective models. PLS predict with 10-fold crossvalidation was used to assess the predictive performance when analyzing new data. Predicted-Oriented Segmentation analysis, Multi-Group Analysis and Measurement Invariance Assessment were employed to examine compositional invariance.

\section{Results}

\section{Sociodemographic and clinical data}

Table 1 shows the sociodemographic and clinical data of the HC and MS patients divided into those with and without an increased EDSS score ( $\geq 3$ as threshold value). This table presents the data on all $\mathrm{HC}$ and the selected group of MS patients who were not treated with folic acid ( $\mathrm{n}=141)$ because all computations (except the genotypic associations) are calculated using this data set. Among these $141 \mathrm{MS}$ patients, 58 (41.1\%) presented mild disability (EDSS $<3$ ) and $83(58.9 \%)$ presented moderate/high disability (EDSS $\geq 3$ ). Univariate analysis showed that MS patients with moderate/high disability were older and showed a higher frequency of MetS than those with mild disability and $\mathrm{HC}(\mathrm{p}<0.001)$. Patients with moderate/high disability showed a higher frequency of SAH and T2DM than HC ( $\mathrm{H}=0.011$ and $p=0.049$, respectively). There were no significant differences regarding sex, BMI, ethnicity and smoking between the three study groups. Patients with moderate/high disability showed higher duration of disease and disability progression than those with mild disability $(p<0.001)$. There were significantly more patients with progressive clinical forms (SPMS+PPMS) in the patient group with EDSS $\geq 3$ as compared with the EDSS $<3$ group.

Table 1 Socio-demographic and clinical data of patients with multiple sclerosis (MS), subdivided according to the EDSS threshold value of $\geq 3$ and healthy controls $(\mathrm{HC})$ 


\begin{tabular}{|c|c|c|c|c|c|c|}
\hline Variables & $\begin{array}{l}\mathrm{HC}^{\mathrm{A}} \\
(\mathrm{n}=226)\end{array}$ & $\begin{array}{l}\text { MS EDSS }<3 \text { B } \\
(n=58)\end{array}$ & $\begin{array}{l}\text { MS EDSS } \geq 3^{c} \\
(n=83)\end{array}$ & $F / X^{2}$ & df & $p$ value \\
\hline Age (years) & $36.3(10.6)^{C}$ & $36.1(10.3)^{C}$ & $46.4(14.0)^{A, B}$ & 25.42 & $2 / 363$ & $<0.001$ \\
\hline Sex (Femae/Male) & $155 / 71$ & $38 / 20$ & $58 / 25$ & 0.311 & 2 & 0.856 \\
\hline $\operatorname{BMI}\left(\mathrm{Kg} / \mathrm{m}^{2}\right)$ & $25.37(4.47)$ & $25.15(4.63)$ & $25.64(5.15)$ & 0.80 & $2 / 356$ & 0.821 \\
\hline MetS (No/Yes) & $182 / 39^{C}$ & $51 / 7^{C}$ & $48 / 28^{A, B}$ & 15.86 & 2 & $<0.001$ \\
\hline Duration of illness (years) & - & $5.57(4.55)^{\mathrm{C}}$ & $8.24(7.76)^{B}$ & 5.54 & $1 / 139$ & 0.020 \\
\hline Clinical forms & & & & - & - & $<0.001$ \\
\hline RRMS & & 58 & 64 & & & \\
\hline SPMS & & 0 & 14 & & & \\
\hline PPMS & & 0 & 05 & & & \\
\hline EDSS & - & $1.01(0.86)^{C}$ & $4.91(1.61)^{B}$ & 282.86 & $1 / 139$ & $<0.001$ \\
\hline MSSS & - & $1.89(1.65)^{C}$ & $7.02(2.20)^{B}$ & 204.33 & $1 / 126$ & $<0.001$ \\
\hline Ethnicity $\mathrm{C} / \mathrm{NC}$ & $179 / 47$ & $47 / 11$ & $58 / 25$ & 3.54 & 2 & 0.170 \\
\hline SAH (No/Yes) & $170 / 21^{C}$ & $49 / 9$ & $62 / 21^{A}$ & 9.11 & 2 & 0.011 \\
\hline T2DM (No/Yes) & $176 / 29^{C}$ & $56 / 2$ & $76 / 7^{A}$ & 6.02 & 2 & 0.049 \\
\hline Smoking (No/Yes) & $200 / 26$ & $54 / 4$ & $70 / 13$ & 2.56 & 2 & 0.278 \\
\hline
\end{tabular}

Continuous variables were expressed as mean (SD); the categorical variables were expressed as number (n); A: healthy controls; B: MS EDSS <3: Multiple sclerosis patients with EDSS < 3; C: MS EDSS $\geq 3$ : Multiple sclerosis patients with EDSS $\geq 3$; df: degree of freedom; BMI: body mass index; MetS: metabolic syndrome; RRMS: relapsing-remitting multiple sclerosis; SPMS: secondary progressive multiple sclerosis; PPMS: primary progressive multiple sclerosis; EDSS: Expanded Disability Status Score; MSSS: Multiple Sclerosis Severity Score; C: Caucasian; NC: non-Caucasian; SAH: systemic arterial hypertension; DMT2: type 2 diabetes mellitus

\section{Biomarker data in MS subgroups}

Table 2 shows the biomarker assessment in $\mathrm{HC}$ and MS patients divided into two subgroups using the EDSS score. Both the $\mathrm{HC}$ group $\left(\chi^{2}=0.01\right.$, $\mathrm{df}=1, \mathrm{p}=0.907)$ and total study group $\left(\mathrm{x}^{2}=0.15, \mathrm{df}=1, \mathrm{p}=0.698\right)$ were in Hardy-Weinberg equilibrium regarding the MTHFR allelic frequencies. The first part of the table (computed on the total sample) shows that there were no significant associations between these diagnostic groups and the MTHFR phenotypes using different genetic models. The second part of the table (calculated on the selected study groups) shows the measurements of the non-genetic biomarkers in the study groups. We found that folate and homocysteine were significantly higher in MS patients than in $\mathrm{HC}$, whereas adiponectin was reduced in both patient groups. There were no significant differences in vitamin D3 and uric acid between the three groups. CRP was significantly higher in patients with an EDSS score $\geq 3$ versus those with EDSS $<3$. The M1, Th1, Th17, and Th2 Treg cytokine values, named IAI, were significantly different between the three study groups and increased from $\mathrm{HC}$ to MS patients with EDSS 3 and to MS patients with EDSS $\geq 3$. The composite score of the levels of TNF-a and their soluble receptors sTNFR1 and sTNFR2 was significantly higher in MS patients with EDSS $\geq 3$ than in the two other groups (EDSS $<3$ and $\mathrm{HC}$ ). These differences remained significant after FDR p-correction. 
Table 2

Genetic and biomarker data in patients with multiple sclerosis (MS) divided according to an EDSS threshold of $\geq 3$ and controls

\begin{tabular}{|c|c|c|c|c|c|c|c|}
\hline Variables & $\begin{array}{l}\text { Controls A } \\
(n=226)\end{array}$ & $\begin{array}{l}\text { MS, EDSS }<3^{B} \\
(n=74)\end{array}$ & $\begin{array}{l}\text { MS, EDSS } \geq 3^{C} \\
(n=89)\end{array}$ & $F / X^{2}$ & df & $p$ value & $R^{2}$ \\
\hline \multicolumn{8}{|c|}{ MTHFR $677 \mathrm{C}>\mathrm{T}$ model } \\
\hline Codominant & $106 / 97 / 23$ & $35 / 31 / 8$ & $41 / 47 / 10$ & 0.94 & 4 & 0.919 & - \\
\hline
\end{tabular}

CC vs. CT vs. TT

\begin{tabular}{|c|c|c|c|c|c|c|}
\hline Dominant & $106 / 120$ & $35 / 39$ & $41 / 57$ & 0.80 & 2 & 0.671 \\
\hline
\end{tabular}

$\begin{array}{llllll}\text { Recessive } & 203 / 23 & 66 / 8 & 88 / 10 & 0.03 & 2\end{array}$

$\mathrm{CC}+\mathrm{CT}$ vs. TT

Overdominant

$129 / 97$

$43 / 31$

$51 / 47$

0.86

2

0.649

CC vs. TT

\begin{tabular}{|c|c|c|c|c|c|c|c|}
\hline Folate $(\mathrm{ng} / \mathrm{mL}) *$ & $6.07(0.40)^{B, C}$ & $10.37(0.78)^{A}$ & $9.61(0.65)^{A}$ & 18.37 & $2 / 253$ & $<0.001$ & 0.127 \\
\hline $\operatorname{Hcy}(\mu \mathrm{mol} / \mathrm{L})^{\star}$ & $10.48(0.27)^{\mathrm{B}, \mathrm{C}}$ & $11.46(0.52)^{\mathrm{A}}$ & $12.67(0.46)^{\mathrm{A}}$ & 10.03 & $2 / 346$ & $<0.001$ & 0.055 \\
\hline Adiponectin $(\mu \mathrm{g} / \mathrm{mL}) *$ & $7.34(0.25)^{B, C}$ & $2.74(0.42)^{A}$ & $2.97(0.39)^{A}$ & 127.59 & $2 / 292$ & $<0.001$ & 0.467 \\
\hline Vitamin D3 $(\mathrm{ng} / \mathrm{mL})$ * & $30.11(0.94)$ & 29.52(1.76) & $30.32(1.56)$ & 0.89 & $2 / 334$ & 0.411 & 0.005 \\
\hline Uric acid $(\mathrm{mg} / \mathrm{dL})^{\star}$ & $4.32(0.08)$ & $4.05(0.15)$ & $4.05(0.13)$ & 2.27 & $2 / 355$ & 0.105 & 0.013 \\
\hline $\mathrm{CRP}(\mathrm{mg} / \mathrm{L})^{*}$ & $3.29(0.67)$ & $2.18(1.31)^{C}$ & $4.97(1.17)^{\mathrm{B}}$ & 2.53 & $2 / 349$ & 0.081 & 0.014 \\
\hline M1 & $-0.562(0.098)^{A, C}$ & $0.189(0.192)^{A, C}$ & $1.014(0.169)^{A, B}$ & 32.89 & $2 / 360$ & $<0.001$ & 0.154 \\
\hline Th1 & $-.579(0.107)^{\mathrm{B}, \mathrm{C}}$ & $0.221(0.209)^{A, C}$ & $0.779(0.183)^{A, B}$ & 21.97 & $2 / 360$ & $<0.001$ & 0.109 \\
\hline Th17 & $-.790(0.104)^{B, C}$ & $0.474(0.203)^{\text {A.C }}$ & $1.166(0.178)^{A, B}$ & 49.37 & $2 / 360$ & $<0.001$ & 0.215 \\
\hline Th2 + Treg & $-.041(0.103)^{B, C}$ & $0.802(0.202)^{A, C}$ & $1.420(0.177)^{\mathrm{A}, \mathrm{B}}$ & 85.95 & $2 / 359$ & $<0.001$ & 0.324 \\
\hline TNF-a + receptors & $-0.178(0.063)^{\mathrm{C}}$ & $-0.159(0.122)^{\mathrm{C}}$ & $0.581(0.107)^{A, B}$ & 18.58 & $2 / 359$ & $<0.001$ & 0.094 \\
\hline \multicolumn{8}{|c|}{$\begin{array}{l}\text { *All results of univariate GLM adjusted for age, sex and Body mass index (BMI), and performed as log transformation. A: healthy controls; } B \text { : } \\
\text { Multiple sclerosis patients with EDSS < 3; C: Multiple sclerosis patients with EDSS } \geq 3 \text {; df: degree of freedom; } \mathrm{R}^{2} \text { : Nagelkerke's peudo-R }{ }^{2} \text { values } \\
\text { were used as effect size measurement. MTHFR } 677 \mathrm{C}>\text { T methylenetetrahydrofolate reductase genetic variant with C as the major allele and T as } \\
\text { the minor allele; Hcy: homocysteine; CRP: C-reactive protein. M1: as zIL-6 + zTNFa; Th1: as zIL-2 + zIFN- }- \text {; Th17: as zIL-17 + zIL-6; Th2 + Treg: as } \\
\text { zIL-4 + zIL-10; TNF-a + receptors: TNF-a + soluble TNF-a receptors: as zTNF-a + zsTNFR1 + zsTNFR2 }\end{array}$} \\
\hline
\end{tabular}

Prediction of MS and subgroups using biomarkers

Table 3, regression \#1, shows the results of a binary logistic regression analysis with MS as dependent variable and $\mathrm{HC}$ as reference group and all biomarkers shown in Table 2 as explanatory variables while allowing for the effects of age, sex, BMI, MetS, SAH, and T2DM. We found that folate, homocysteine, IAI, and age (all positively), adiponectin (negatively) and female sex were significant predictors of $M S(X 2=327.38, \mathrm{df}=6, \mathrm{p}<0.001)$ with a Nagelkerke pseudo- $\mathrm{R}^{2}$ value of 0.788 and an accuracy of $89.0 \%$ (sensitivity $=84.7 \%$ and specificity $=92.2 \%$ ). The $M T H F R 677 \mathrm{C}>\mathrm{T}$ genotypes were not significant in this model. Regression \#2 shows that the disability (MS patients with EDSS $\geq 3$ versus those with EDSS $<3$ as reference group) was significantly $(\chi 2=31.69, \mathrm{df}=3, \mathrm{p}<0.001)$ associated with increased age, IAl, and CRP (all positively) with a Nagelkerke pseudo- ${ }^{2}$ value of 0.271 and an accuracy of $71.6 \%$ (sensitivity $=74.7 \%$ and specificity=67.2\%). The MTHFR genotypes were again not significant. 
Table 3

Results of binary logistic regression analysis with multiple sclerosis patients with EDSS $\geq 3$ as dependent variable

\begin{tabular}{|c|c|c|c|c|c|c|c|}
\hline $\begin{array}{l}\text { Dependent } \\
\text { Variables }\end{array}$ & $\begin{array}{l}\text { Explanatory } \\
\text { variables }\end{array}$ & B & SE & $\begin{array}{l}\text { Wald } \\
(\mathrm{df}=1)\end{array}$ & $p$ value & OR & $95 \% \mathrm{Cl}$ \\
\hline \multirow[t]{6}{*}{ MS vs. HC } & Adiponectin & -2.718 & 0.381 & 53.62 & $<0.001$ & 0.06 & $0.03-0.13$ \\
\hline & Folate & 1.535 & 0.304 & 25.44 & $<0.001$ & 4.64 & $2.56-8.43$ \\
\hline & Homocysteine & 1.116 & 0.247 & 20.45 & $<0.001$ & 3.05 & $1.88-4.95$ \\
\hline & $|A|$ & 2.052 & 0.479 & 18.39 & $<0.001$ & 7.79 & $3.05-19.90$ \\
\hline & Sex (male) & -1.870 & 0.483 & 15.00 & $<0.001$ & 0.15 & $0.06-0.40$ \\
\hline & Age & 0.056 & 0.017 & 11.40 & 0.001 & 1.06 & $1.02-1.09$ \\
\hline \multirow{3}{*}{$\begin{array}{l}\text { EDSS } \geq 3 \\
\text { vs. EDSS }<3\end{array}$} & Age & 0.062 & 0.016 & 14.30 & $<0.001$ & 1.06 & $1.03-1.10$ \\
\hline & $|A|$ & 0.760 & 0.355 & 4.59 & 0.032 & 2.14 & $1.06-4.28$ \\
\hline & CRP & 0.444 & 0.208 & 4.56 & 0.033 & 1.56 & $1.04-2.34$ \\
\hline \multicolumn{8}{|c|}{ OR: odds ratio; Cl: confidence interval; MS: Multiple Sclerosis; HC: healthy controls. } \\
\hline \multicolumn{8}{|c|}{$\begin{array}{l}\text { EDSS: Expanded Disability Status Score; IAl: inflammatory activity index, computed as first principal component extracted from M1, Th1, Th17, } \\
\text { Th2Treg, TNF-a + TNFR1 + TNFR2: M1: zIL-6 + zTNFa; Th1: zIL-2 + zIFN-y; Th17: zIL-17 + zIL-6; Th2 + Treg: zIL-4 + zIL-10; TNF-a + receptors: } \\
\text { TNF-a + soluble TNF-a receptors: zTNF-a + zsTNFR1 + zsTNFR2; CRP: C-reactive protein }\end{array}$} \\
\hline
\end{tabular}

\section{Prediction of EDSS and MSSS scores by biomarkers}

Table 4 shows the results of multiple regression analyses with the MS-EDSS-MSSS scores as dependent variables and all biomarkers as explanatory variables while allowing for the age, sex, BMI, SAH, and T2DM. We found that $21.8 \%$ of the variance in the EDSS score in MS patients was explained by age, IAI and CRP (all positively associated). IAI and CRP (both positively) and vitamin D3 (negatively) predicted $10.9 \%$ of the variance in the MSSS score. Not one of the genotypic MTHFR $677 \mathrm{C}>\mathrm{T}$ models was significant in this regression model. The third multiple regression in Table 4 shows that $54.4 \%$ of the variance in the MS-EDSS-MSSS score was explained by the regression on age, IAI, homocysteine, folate, and CRP (all positively associated) and adiponectin, BMI, and vitamin D3 (all negatively associated), female sex and the MTHFR TT genotype. 
Table 4

Results of multiple regression analysis of multiple sclerosis patients with EDSS and MSSS as dependent variables and biomarkers as explanatory variables

\begin{tabular}{|c|c|c|c|c|c|c|c|c|}
\hline $\begin{array}{l}\text { Dependent } \\
\text { variables }\end{array}$ & $\begin{array}{l}\text { Explanatory } \\
\text { variables }\end{array}$ & $\beta$ & $f$ & $p$ value & $F$ & df & $p$ value & $\mathbf{R}^{2}$ \\
\hline \multirow{4}{*}{$\begin{array}{l}\text { EDSS in } \\
\text { MS }\end{array}$} & Model \#1 & & & & 13.59 & $3 / 146$ & $<0.001$ & 0.218 \\
\hline & Age & 0.329 & 4.34 & $<0.001$ & & & & \\
\hline & $|A|$ & 0.148 & 2.70 & 0.008 & & & & \\
\hline & CRP & 0.162 & 2.16 & 0.033 & & & & \\
\hline \multirow{4}{*}{$\begin{array}{l}\text { MSSS in } \\
\text { MS }\end{array}$} & Model \#2 & & & & 5.97 & $3 / 146$ & 0.001 & 0.109 \\
\hline & $|A|$ & 0.199 & 2.55 & 0.012 & & & & \\
\hline & CRP & 0.184 & 2.35 & 0.020 & & & & \\
\hline & Vitamin D3 & -0.157 & -2.01 & 0.046 & & & & \\
\hline \multirow{12}{*}{$\begin{array}{l}\text { EDSS+MSSS } \\
+ \text { MS in all subjects }\end{array}$} & Model \#3 & & & & 43.39 & $10 / 363$ & $<0.001$ & 0.544 \\
\hline & Adiponectin & -0.427 & -10.08 & $<0.001$ & & & & \\
\hline & Age & 0.211 & 5.28 & $<0.001$ & & & & \\
\hline & $\mid \mathrm{AI}$ & 0.250 & 6.54 & $<0.001$ & & & & \\
\hline & Homocysteine & 0.239 & 6.06 & $<0.001$ & & & & \\
\hline & Folate & 0.162 & 4.10 & $<0.001$ & & & & \\
\hline & Sex & -0.097 & -2.48 & 0.014 & & & & \\
\hline & CRP & 0.129 & 3.22 & 0.001 & & & & \\
\hline & $\mathrm{BMI}$ & -0.113 & -2.86 & 0.004 & & & & \\
\hline & MTFHR $677 C>T$ & -0.086 & -2.38 & 0.018 & & & & \\
\hline & (recessive model) & & & & & & & \\
\hline & Vitamin D3 & -0.072 & -1.98 & 0.049 & & & & \\
\hline
\end{tabular}

df: degree of freedom; $\mathrm{R}^{2}$ : Nagelkerke's peudo- $\mathrm{R}^{2}$ values were used as effect size measurement. EDSS: Expanded Disability Status Score; MSSS: Multiple Sclerosis Severity Score; IAl: inflammatory activity index, computed as first principal component extracted from M1, Th1, Th17, Th2,

Treg, TNF-a + TNFR1 + TNFR2; CRP: C-reactive protein; BMI: body mass index; MTHFR 677C>T methylenetetrahydrofolate reductase genetic variant with $\mathrm{C}$ as the major allele and $\mathrm{T}$ as the minor allele: recessive model: $\mathrm{CC}+\mathrm{CT}$ Vs. TT

\section{Prediction of homocysteine and folate using MTHFR 677C>T genotypes}

Table 5 shows the results of multiple regression analyses with homocysteine as dependent variable and folate and MTHFR genotypes as explanatory variables while allowing for the effects of age, sex, and BMI. In the total study group, we found that $16.6 \%$ of the variance in homocysteine was explained by the MTHFRTT genotype and age (both positively) and folate (negatively) and male sex. In the HC group, the same variables predicted $15.9 \%$ of the variance in homocysteine levels. In the total study group, $4.5 \%$ of the variance in folate levels was predicted by the MTHFR additive model (negatively) and age (positively). We found that $11.7 \%$ of the variance in the IAI was explained by the regression on adiponectin and age (both negatively) and folate (positively). The MTHFR genotypic models were not significant in this regression. 
Table 5

Results of multiple regression analysis of multiple sclerosis patients with homocysteine and folate as dependent variables and biomarkers as explanatory variables

\begin{tabular}{|c|c|c|c|c|c|c|c|c|}
\hline $\begin{array}{l}\text { Dependent } \\
\text { variables }\end{array}$ & $\begin{array}{l}\text { Explanatory } \\
\text { variables }\end{array}$ & $\beta$ & $\mathbf{F}$ & $\mathrm{p}$ value & $\mathbf{F}$ & df & $\mathrm{p}$ value & $\mathrm{R}^{2}$ \\
\hline \multirow{5}{*}{$\begin{array}{l}\text { Hcy in all } \\
\text { subjects }\end{array}$} & Model \#1 & & & & 18.44 & $4 / 370$ & $<0.001$ & 0.166 \\
\hline & Age & 0.301 & 6.23 & $<0.001$ & & & & \\
\hline & Folate & -0.173 & -3.56 & $<0.001$ & & & & \\
\hline & Sex & 0.178 & 3.74 & $<0.001$ & & & & \\
\hline & MTHFR $677 \mathrm{C}>\mathrm{T}$ recessive model & 0.129 & 2.69 & 0.007 & & & & \\
\hline \multirow[t]{5}{*}{ Hcy in $\mathrm{HC}$} & Model \#2 & & & & 10.37 & $4 / 220$ & $<0.001$ & 0.159 \\
\hline & Folate & -0.269 & -4.25 & $<0.001$ & & & & \\
\hline & MTHFR $677 \mathrm{C}>\mathrm{T}$ recessive model & 0.187 & 3.01 & 0.003 & & & & \\
\hline & Age & 0.168 & 2.67 & 0.008 & & & & \\
\hline & Sex & 0.159 & 2.57 & 0.011 & & & & \\
\hline \multirow{4}{*}{$\begin{array}{l}\text { Folate in } \\
\text { all subjects }\end{array}$} & Model \#1 & & & & 8.78 & $2 / 372$ & $<0.001$ & 0.045 \\
\hline & Age & 0.178 & 3.51 & 0.001 & & & & \\
\hline & $M T H R$ 677C>T & -0.118 & -2.33 & 0.020 & & & & \\
\hline & Additive model & & & & & & & \\
\hline \multirow[t]{4}{*}{ IAI in all subjects } & Model \#2 & & & & 16.34 & $3 / 370$ & $<0.001$ & 0.117 \\
\hline & Adiponectin & -0.267 & -5.28 & $<0.001$ & & & & \\
\hline & Folate & 0.143 & 2.78 & 0.006 & & & & \\
\hline & Age & -0.124 & -2.51 & 0.013 & & & & \\
\hline
\end{tabular}

\section{Results of PLS analysis}

The associations between the MTHFR genotypic models and homocysteine with folate as putative mediator (while allowing for the effects of age, sex, and BMI) were firstly examined in the HC group. Figure 1 shows the results of complete PLS path analysis conducted on 5.000 bootstrap samples. We found that $15.9 \%$ of the variance in homocysteine was explained by the TT genotype, age, and folate (all positively) and male sex. In addition, $5.7 \%$ of the variance in folate was predicted by the additive MTHFR genotype. Most importantly, the specific indirect effect of this additive model on homocysteine mediated by folate was not significant $(t=1.64, p=0.14)$. Folate partly mediated the effects of age on homocysteine ( $t=2.45$, $p=0.014)$. All in all, there were significant direct effects of the TT genotype, but not any of the other genotypes, on homocysteine.

Consequently, we have examined the same associations in the total study group after entering the other biomarkers of MS, namely IAI (entered as a latent vector extracted from the M1, Th1, Th17 and Th2Treg cytokine profiles), adiponectin, uric acid, age, sex, CRP, BMI (all entered as single indicators). The final outcome variable, named MS-EDSS-MSSS, was a latent vector extracted from MS, EDSS, and MSSS, which thus is an index of MS and its severity. We used a multi-step multiple mediation model whereby the effects of the MTHFR genotypes (recessive and additive models), age, sex and BMI could be explained by the biomarkers. Figure 2 shows the PLS path model using complete PLS path analysis on 5.000 bootstrap samples and after feature selection, PLS predict analysis, prediction-oriented segmentation with multi-group analysis. This figure shows only the significant pathways. The overall fit of this model was adequate with SRMR $=0.019$. Moreover, the construct reliabilities of both latent vectors were adequate, namely Cronbach $a>0.9$, rho $A$ and composite reliability $>0.936$, and AVE $>0.78$. The outer model loadings on both latent vectors were all $>0.82$ with $p<0.0001$. Blindfolding showed that the construct cross-validated redundancies were adequate, namely the MS latent vector 0.099 and IAI 0.480 . We found that $56.0 \%$ of the variance in MS-EDSS-MSSS latent vector was explained by the direct effects of adiponectin and uric acid (both negatively), homocysteine, folate, CRP, and age (all positively). Furthermore, $33.8 \%$ of the variance in uric acid was explained by age, sex and $\mathrm{BMI}$, and $20.2 \%$ of the variance in CRP by sex and BMI. 
Most importantly, there were significant indirect effects of the MTHFRTT genotype on MS mediated by homocysteine ( $\mathrm{t}=2.01, \mathrm{p}=0.022)$ and of MTHFR additive model which was mediated by folate $(\mathrm{t}=-2.01, \mathrm{p}=0.045)$. There were no other significant indirect effects or direct effects of $M T H F R$ genotypes on the MS-EDSS-MSSS index. Nevertheless, analyses of the total direct effects showed that only the MTHFR TT genotype ( $\mathrm{t}=2.22$, $\mathrm{p}=0.027)$, but not the additive model $(\mathrm{t}=-1.87, \mathrm{p}=0.062)$ had a significant effect on MS-EDSS-MSSS. Predicted-Oriented Segmentation analysis coupled with Multi-Group Analysis and Measurement Invariance Assessment showed that full compositional invariance was obtained. The $\mathrm{Q}^{2}$ Predict values of all endogenous construct indicators were positive indicating that they outperform the most naïve benchmark (the prediction error is smaller than the error of the most naïve benchmark).

\section{Discussion}

The main result of the present study is that the MTHFR $677 \mathrm{C}>\mathrm{T}$ variant exerts indirect effects on MS susceptibility through the increased levels of homocysteine (but not folate) associated with the TT genotype in a recessive model. In fact, homocysteine levels exert a direct effect on the inflammatory response expressed as the IAI index and thus on the MS disability progression. Another important result is that the MTHRF 677C>T genotypes did not show a direct effect on the disability as well as disability progression of the MS patients. Other biomarkers showed an effect on the EDSS and MSSS scores, such as age, IAI, and CRP. These biomarkers, together, exerted a strong effect on the disability, as assessed with the EDSS. Moreover, a panel of the IAI, CRP, and vitamin D3 biomarkers exerted a modest effect on disability progression. On the other hand, the MTHFR 677C>T genotype had a partial effect on the MS diagnosis, disability and disability progression. In fact, other variables were also involved in these clinical biomarkers of the MS.

\section{MTHFR C677T and multiple sclerosis and homocysteine}

Our results are in agreement with previous studies which found no association between the MTHFR 677C>T variant and MS susceptibility [44-47]. The role of the MTHFR 677C>T variant in the pathophysiology of MS has been evaluated in some genetically specific worldwide populations with inconsistent results. While three case-control studies [48-50] demonstrated an association between the T allele with MS, others failed to confirm this association [44-47]. Tajouri et al. genotyped the MTHFR 677C>T variant among Australian MS patients and unaffected control subjects, matched for sex, age and ethnicity and, although the TT homozygous genotype was slightly over-represented in the MS group than controls, the difference failed to reach statistical significance and, according to these authors, their result could not support a major role for this functional gene variation in MS susceptibility [47]. Further, Cevik et al. found that the T allele of MTHFR 677C>T variant was associated with MS susceptibility [48]. Naghibalhossaini et al. reported that the CT genotype of MTHFR $677 \mathrm{C}>\mathrm{T}$ showed a higher risk of MS incidence for both cases with the recessive (TT vs. CT + CC) and codominant (CT vs. CC) pattern of inheritance in comparison with controls [49]. These results point to the need for additional studies involving individuals from other world populations.

Different factors may account for these apparent conflicting results. First, the heterogenic clinical characteristics of the MS as different groups of patients may have various genetic factors which predispose to the disease. Second, some alleles of candidate genes may be strongly associated with the disease in one population, whereas in another this association may be weak or not observed due to the presence of other genetic factors or genetic by environment interactions, including smoking, diet, and lifestyle habits [51]. Third, MS development cannot be predicted based on genotype alone because even the strongest major histocompatibility complex (MHC) class II- linked risk genes for MS are incompletely penetrant [52]. These authors affirm that the incomplete penetrance of MS susceptibility alleles probably reflects interactions with other genes, post transcriptional regulatory mechanisms, and significant nutritional and environmental influences. Therefore, modifiable environmental exposures may determine whether MS develops in individuals who carry risk genes. Fourth, conflicting results about the association between MTHFR and MS could be explained by the study design, the sample size of the study, the time points of testing the biomarkers and, technically, by different laboratory methods for the measurement of the homocysteine and folate, as well as for the MTHFR genotyping analysis.

In the present study, our results showed that in all subjects $16.6 \%$ of the variance of homocysteine was explained by the TT genotype independently from age, folate, and sex. Therefore, higher homocysteine levels were observed among the patients carrying the TT genotype than those carrying the CC + TT genotype (recessive model). The association between the MTHFR 677C>T variant and high levels of homocysteine is well established in the general population $[53,54,55]$, as well as in patients with other diseases $[56,57,58]$. The MTHFR enzyme activity is $55-65 \%$ reduced among individuals carrying the TT genotype and $25 \%$ reduced among those carrying the CT genotype compared with the enzyme activity of individuals carrying the CC genotype $[28,57]$.

Homocysteine is a sulfur-containing amino acid and an important intermediate product in the methionine metabolism. The MTHFR enzyme plays a role in folate metabolism where it catalyzes the reduction of 5,10-methylenetetrahydrofolate to 5-methyltetrahydrofolate, which is required for methylation and conversion of homocysteine to methionine. This enzyme functions at the junction between two critical pathways regulating one carbon metabolism, nucleotide synthesis and synthesizing the universal methyl donor S-adenosyl methionine (SAM). Patients with a deficiency in the MTHFR present increased levels of homocysteine [16].

Regarding the folate levels and the genetic variant investigated in this study, our results demonstrated that the folate levels, age and the MTHFR C677T variant in a dominant model (CC vs. CT vs. TT) explained $4.5 \%$ of the variance in folate levels in all individuals. Individuals carrying the CT

Page $10 / 19$ 
genotype showed an intermediate folate phenotype between those carrying the two homozygous genotypes (CC and TT), with the highest levels of folate in those carrying the $\mathrm{CC}$, intermediate values in those with the CT genotype and the lowest among the TT carriers. Our hypothesis that the MTHFR $677 \mathrm{C}>\mathrm{T}$ variant (in a recessive model CC+CT vs. TT) modulates homocysteine and folate levels could be confirmed. In addition, in MS, $15.9 \%$ of the variance in homocysteine is explained by this variant and the same explanatory variables.

\section{Homocysteine and folate levels in multiple sclerosis}

Our results of the present study showed that MS patients had higher levels of homocysteine and folate than controls. Several studies have focused on the role of homocysteine, vitamin B12, and folate as possible participants in the neurodegenerative process [59]. Previous studies have reported increased plasma levels of homocysteine in MS patients when compared to controls $[8,29,30]$. We previously demonstrated that homocysteine levels are increased in MS patients, and that hyperhomocysteinemia was associated with disease progression evaluated by the MSSS [8]. Li et al., in a meta-analysis, showed that patients with MS had higher levels of homocysteine compared with controls and that there were no significant differences for vitamin B12 or folate levels between MS and controls. In a subgroup analysis, these authors demonstrated that there was a significant difference in homocysteine between relapsing-remitting MS (RRMS) patients and controls but no significant difference in homocysteine between patients with SPMS or PPMS and controls [51].

In agreement with previous studies, we found that high levels of homocysteine were positively associated with MS and these findings underscore that hyperhomocysteinemia may be a risk factor of this neuroinflammatory disease $[7,10]$. Studies have shown that high levels of homocysteine are toxic to neural cells and cause neuronal damage by several mechanisms. First, homocysteine may sensitize neurons to oxidative stress via oxidation of sulfhydryl groups subsequently resulting in generation of ROS, such as superoxide and hydrogen peroxide [11, 60]. Second, promoting excitotoxicity via stimulation of N-methyl-D-aspartate receptors (NMDA), damaging neuronal DNA thereby triggering apoptosis and cell death [12, 61, 62]. Third, elevated levels of homocysteine lead to CNS inflammation [63], interfere with T and B lymphocyte responses [64] and reduce Sadenosyl methionine (SAM) levels, which play an important role in myelin basic protein (MBP) methylation [65]. Modifications involving methylation could destabilize myelin structures by triggering hypomethylation of myelin basic protein, a cardinal component of myelin in the CNS [66].

Another major finding of this study is that adiponectin, age, sex, BMI, MTHFR 677C>T variant, homocysteine, vitamin D3, folate, and CRP explain $54.4 \%$ of the variance in MS and its severity. The latter index combinates the diagnosis of MS, EDSS, and MSSS into a composite score, which reflects MS and its severity, including disabilities and disability progression. Previous papers showed inconsistent results regarding folate levels in MS. Some studies showed decreased levels of folate in MS patients compared to controls [29, 30] while other studies reported no differences between patients with MS and controls $[32,67,68]$. Meta-analysis studies showed no significant difference in folate levels between MS patients and controls $[7,51,59]$. However, two of these meta-analysis $[7,59]$ failed to take some critical factors into account, including sex, age, disease phase and/or severity, and/or ethnicity of study populations. A case-control and meta-analysis showed no significant difference in levels of folate and in the frequency of folate deficiency in MS patients compared to controls [9].

Several previous studies have investigated the roles of homocysteine, vitamin B12, and folate in MS since myelin replacement requires normal function of folate-vitamin B12 methylation pathway, which is vital to provide methyl groups for myelin regeneration [69]. Folate and vitamin B12 are needed in the process of methionine-synthase mediating the conversion of homocysteine to methionine. Both 5-methyltetrahydrofolate and methylvitamin B12 are essential factors for methionine synthesis of homocysteine [70]. It is well established that the deficiency of vitamin B12 and folate may cause increased homocysteine. Previous studies included in the meta-analysis [51] showed high heterogeneity, which could have a certain impact on the apparent discrepant results regarding the folate and MS. In addition, some studies have explicitly restricted that subjects had not received folic acid supplementation, while others did not control the effects of confounding factors such as diet and drugs, which may interfere with the association between folate and MS.

In contrast with some previous studies, we observed high levels of folate in MS as compared with controls [29, 30]. There are three possible explanations. First, MS patients could have a lower expression of the folate receptor (FR)- $\beta$ than controls. Healthy cells acquire their folate (or folic acid as supplement) using reduced folate carriers and/or the proton-coupled folate transporter, which are needed for normal cell survival and proliferation. However, during inflammation, folate uptake by activated macrophages is mediated primarily by the beta isoform of FR (FR- $\beta$ ) which exhibits approximately 1000 higher affinity for folate than the reduced folate carrier [71, 72]. A recent study [73] showed that macrophages express FR- $\beta$ during the active phase of MS, according to animal experiments and tissue autopsy from MS patients versus controls. Because all our MS patients were in the remission phase of the disease, there would be a lower expression of FR- $\beta$ in the cells and, therefore, greater availability of folate in the circulation than controls. In addition, macrophages expressing functional FR- $ß$ are present in both CNS and peripheral sites of inflammation [74].

The second hypothesis is that increased homocysteine may reduce the expression of human FR-a. These authors propose that low levels of homocysteine increase FR-a expression and that high doses have an opposite effect. Since our MS patients show high levels of homocysteine, we may assume that they have a decreased expression of FR- $a$, with less internalization of folate into the cells, resulting in increased levels in the circulation. The third hypothesis is that the MTHFR 677C>T variant may be associated with the production of autoantibodies against FR [75]. The

Page $11 / 19$ 
latter authors observed that plasma levels of FR autoantibodies in women with the TT genotype at MTHFR 677C>T were significantly higher than those of women with the CC genotype [76, 77]. By inference, since the frequency of the TT genotype was higher among the MS patients than controls, folate transport could be impaired. Although these three aforementioned hypotheses may have some reasonableness, the present study did not allow us to elucidate the precise mechanism of high levels of folate were found in patients with MS compared to controls.

\section{Inflammation, homocysteine, MS disability and disability progression}

Regarding the combination of a panel of biomarkers associated with MS, our results showed that adiponectin levels and sex male were negatively associated with MS, while folate and homocysteine, IAI and age were positively associated with MS. Studies have identified a strong association between high levels of homocysteine and inflammation in both human and experimental models [78, 79]. An experimental study showed that high levels of homocysteine induce inflammatory responses in mouse brain through of the activation of microglial cells and increased expression of proinflammatory cytokines such as IL-1 $\beta$ and TNF-a [80]. Previous study reported association between homocysteine and inflammation that include mechanisms the expression of adhesion molecules, leukocyte adhesion, endothelial dysfunction, oxidative stress, and reduced nitric oxide bioavailability [81].

Human and experimental studies showed that MS is not governed by a particular cytokine but instead involves a complex interplay between proand anti-inflammatory cytokines [82]. Taken this into account, our study evaluated a broad inflammatory and anti-inflammatory cytokine profile, expressed as the IAI, a score computed as first principal component extracted from the main cytokines produced by M1, Th1, Th17, Th2, and Treg cells, as well as TNF- $a+$ sTNFR1 + sTNFR2 values. We found that MS was characterized by high levels of the IAl, in agreement with previous studies, findings which again show the important role of an imbalance between inflammatory and anti-inflammatory responses as a major factor in the pathophysiology of MS [83, 84, 85]. We also showed, in previous studies, increased TNF-a, IL-17, and IFN-y in MS patients than in controls [86]. Another study showed that the change in EDSS during a follow-up of 16 months was associated with changes in IL-17 (positively) and IL-4 (negatively) independently from the clinical MS forms, treatment modalities, smoking, age and systemic arterial hypertension. This study also showed that, in addition to homocysteine, IL-6 and IL-4 levels were positively associated with progressive forms of MS vs RRMS while 25(OH)D was negatively associated [87].

Adiponectin is the most abundant anti-inflammatory adipokine in the plasma and regulates the pro-inflammatory nuclear factor kappa B (NF-kB) signaling pathway [88], decreases the expression of the pro-inflammatory cytokines TNF-a, IL-6, and IFN- $\gamma$, and increases the expression of antiinflammatory molecules, such as IL-10 and IL-1 receptor antagonist (IL-1Ra) [89], underscoring its role in the modulation of the inflammatory response in MS [90].

We found that age, IAI, and CRP were associated with moderate/high disability in MS (EDSS $\geq 3$ ). Moreover, IAI and CRP were positively associated with disability progression (MSSS), whereas vitamin D3 was negatively associated. These results are in agreement with previous studies [87, 91, 92] showing that vitamin D3 deficiency is associated with progression of disability in MS patients. Vitamin D3 exerts important immunomodulatory effects and has been associated with the regulation of inflammatory response [91, 93], for example, by inhibiting the NF-kB pathway [94], downregulating pro-inflammatory cytokines, such as TNF-a, IL-6, IL-12, and IFN- $y$, and upregulating anti-inflammatory Treg and Th2 cells and their cytokines [95]. These findings underscored that several mechanisms underlie disease progression independent of relapses. Although all the MS patients were in remission clinical phase of the disease, we observed that the disease progression is occurring. Although are available at least 12 drugs approved as disease-modifying treatments for MS, the major challenge for the clinicians is the identification, at the disease onset, of the subjects most likely to develop an aggressive, quickly progressing form of the disease in order to start with high-impact treatments before severe disability builds up. At the same time, patients with mild forms should avoid overtreatment, with substantial benefits in terms of safety, quality of life and overall allocation of resources $[96,97]$.

The findings in this report are subject to at least four limitations. First, the case-control design does not allow inferences on causal relationship between the studied variables. Second, some important lifestyle factors which could potentially confounder the results, including dietary and vitamin B12 levels, were not controlled. Third, the evaluation of one specific genetic variant (MTHFR 677C >T), which precludes the assessment of how other genetic factors may impact on the complex relationship between multifactorial etiology of MS. Fourth, the study included patients with different clinical forms of MS, as well as treated with different MS therapies; however, all the patients were in remission clinical phase of the disease and the results were adjusted by clinical forms and MS therapy. Notwithstanding these limitations, some strengths should be emphasized, such as the integration of MS patient data with new measures composites of existing biomarkers, such as IAI, TNF- $\mathrm{a}+$ its receptors, and MS-EDSSMSSS, this last one which may better reflect the MS disease course. Moreover, the study used robust methods for the MTHFR 677C>T genotyping, measurement of laboratory biomarkers, and the in-depth statistical models.

\section{Conclusion}

Taken all together, these findings provide important insights into the role of the MTHFR 677C>T, homocysteine, folate and inflammatory response in the underlying pathophysiological mechanisms of MS. Although the MTHFR 677C>T variant was not directly associated with MS, disability, and disability progression, the TT genotype exert indirect effects on MS susceptibility and disability mediated by homocysteine but not folate these results underscore the complex interaction between the genetic factors, with inflammatory and anti-inflammatory mechanisms in the susceptibility, 
disability and disability progression of MS and suggest other possible new targets that may contribute to outline the concept of precision medicine to the MS management and improved care of the patients.

\section{Declarations}

\section{Funding}

The study was supported by Coordination for the Improvement of Higher Level of Education Personnel (CAPES) of Brazilian Ministry of Education: Finance Code 001.

\section{Conflict of interest}

There is no conflict of interest to declare. None of the authors are involved in the publication process or have a financial or other beneficial interest in the products or concepts mentioned in the submitted manuscript.

\section{Availability of data and material}

The data and materials are available.

\section{Authors' contributions}

1) conception and design of the study: ANCS, EMVR, MM; 2) acquisition of data: CMR, SRO, TF, DFA; 3) laboratory analysis: CMR, TF, DFA, MABL; 4) statistical analysis: MM; 5) analysis and interpretation of data: CMR, SRO, ANCS, MM, EMVR; 5) drafting of the manuscript, tables and figures: CMR, SRO, MM, EMVR; 6) manuscript review: CMR, SRO, MM, EMVR. All authors have read and approved the final manuscript.

\section{Compliance with ethical standards}

The protocol was approved by the Institutional Research Ethics Committees of University of Londrina, Paraná, Brazil (CAAE: 22290913.9.0000.5231) and all of the individuals invited were informed in detail about the research and gave written informed consent.

\section{Human rights}

All procedures performed in this study involving human participants were in accordance with the ethical standards of the Institution and/or National Research Committee and with the World Medical Association 1964 Helsinki Declaration.

\section{Standards for reporting}

The manuscript was prepared taken into account the recommendations of the guidelines hosted by the Strengthening the Reporting of Observational studies in Epidemiology (STROBE). STROBE is used for observational studies (cohort, case-control, or cross-sectional designs) according to the STROBE statement (www.strobe-statement.org)

\section{Consent to participate}

Informed consent was obtained from all individual participants included in the study.

\section{Consent for publication}

The studied participants were informed about the present research, and a written consent form was taken from all of them before their enrollment. Moreover, all the authors and co-authors participated and contributed sufficiently in the research, and all of them concur with the submission. The manuscript has been approved by the responsible authorities where the work was carried out. The authors also concur that, if accepted, the manuscript shall not be published elsewhere in the same form in either the same or any other language, without the consent of the Editor-in Chief of Molecular Neurobiology.

\section{Acknowledgements}

The authors thank all the laboratory technicians of the Clinical Immunology Laboratory of University Hospital of Londrina for their support on this study.

\section{References}

1. Karussis D (2014) The diagnosis of multiple sclerosis and the various related demyelinating syndromes: a critical review. J Autoimmun 4849:134-142. https://doi: 10.1016/j.jaut.2014.01.022.

2. Dyment DA, Ebers GC, Sadovnick AD (2004) Genetics of multiple sclerosis. Lancet Neurol 3: 104-110. doi: 10.1016/s1474-4422(03)00663-x 
3. Ineichen BV, Keskitalo S, Farkas M et al (2014) Genetic variants of homocysteine metabolism and multiple sclerosis: a case-control study. Neurosci Lett 562: 75-78. doi: 10.1016/j.neulet.2014.01.008

4. Miller A, Korem M, Almog R et al (2005) Vitamin B12, demyelination, remyelination and repair in multiple sclerosis. J Neurol Sci 233: 93-97. doi: 10.1016/j.jns.2005.03.009

5. Nylander A, Hafler DA (2012) Multiple sclerosis. J Clin Invest 122: 1180-1188. doi: 10.1172/JCI58649

6. Sumelahti ML, Tienari PJ, Hakama M et al (2003) Multiple sclerosis in Finland: incidence trends and differences in relapsing remitting and primary progressive disease courses. J Neurol Neurosurg Psychiatry 74: 25-28. doi: 10.1136/jnnp.74.1.2

7. Zhu Y, He ZY, Liu HN (2011) Meta-analysis of the relationship between homocysteine, vitamin B12, folate, and multiple sclerosis. J Clin Neurosci 18(7):933-938. doi: 10.1016/j.jocn.2010.12.022

8. Oliveira SR, Flauzino T, Sabino BS et al (2018) Elevated plasma homocysteine levels are associated with disability progression in patients with multiple sclerosis. Metab Brain Disease 33(5):1393-1399. doi: 10.1007/s11011-018-0224-4

9. Pan L, Yin Y, Chen J et al (2019) Homocysteine, vitamin B12, and folate levels in patients with multiple sclerosis in Chinese population: A casecontrol study and meta-analysis. Mult Scler Relat Disord 36:101395. doi: 10.1016/j.msard.2019.101395.

10. Seshadri S (2006) Elevated plasma homocysteine levels: risk factors or risk marker for the development of dementia and Alzheimer 's disease? J Alzheimer Dis 9:393-398. doi: 10.3233/jad-2006-9404.

11. Faraci FM, Lentz SR (2004) Hiperhomocysteinemia, oxidative stress and cerebral vascular dysfunction. Stroke 35:345-347. doi: 10.1161/01.STR.0000115161.10646.67.

12. Ho PI, Ortiz D, Rogers E et al (2002) Multiple aspects of homocysteine neurotoxicity: glutamate excitotoxicity, kinase hyperactivation and DNA damage. J Neurosci Res 70 (5):694-702. doi: 10.1002/jnr.10416.

13. Zeng Q, Li F, Xiang T et al (2017) Influence of food groups on plasma total homocysteine for specific MTHFR C677T genotypes in Chinese population. Mol Nutr Food Res 61(2):1600351. doi: 10.1002/mnfr.201600351

14. Ghosh K, Khare A, Shetty S (2007) Fasting plasma homocysteine levels are increased in young patients with acute myocardial infarction from Western India. Indian Heart J 59(3): 242-245

15. Nikfardjam M, Graf S, Hornykewycz S et al (2001) Homocysteine plasma levels in young patients with coronary artery disease. Relation to history of acute myocardial infarction and anatomical extent of disease. Thromb. Res 103 (Suppl. 1): S35-S39. doi: 10.1016/s00493848(01)00295-x

16. Goyette P, Pai A, Milos R et al (1998) Gene structure of human and mouse methylenetetrahydrofolate reductase (MTHFR). Mamm Genome Aug;9(8):652-656. doi: 10.1007/s003359900838. Erratum in: Mamm Genome 1999; 10(2):204.

17. Brattström L, Wilcken DE, Ohrvik J et al (1998) Common methylenetetrahydrofolate reductase gene mutation leads to hyperhomocysteinemia but not to vascular disease: the result of a meta-analysis. Circulation 98(23):2520-2526. doi: 10.1161/01.cir.98.23.2520

18. Frosst P, Blom HJ, Milos R et al (1995) A candidate gene risk factor for vascular disease: a common mutation in methylenetetrahydrofolate reductase. Nat. Genet 10: 111-113. doi: 10.1038/ng0595-111

19. Weisberg I, Tran P, Christensen B et al (1998) A second genetic polymorphism in methylenetetrahydrofolate reductase (MTHFR) associated with decreased enzyme activity. Mol Gen Metab 64:169-172. doi: 10.1006/mgme.1998.2714

20. Kim NK, Kang GD, Kim HJ (2002) Genetic polymorphisms of 5,10-methylenetetrahydrofolate reductase (MTHFR C677T and A1298C) in healthy Koreans. Korean J Genet 24:227-234.

21. Franco RF, Araujo AG, Guerriero JF et al (1998) Analysis of the 677 CT mutation of the methylenetetrahydrofolate reductase gene in different ethnic groups. Thromb Haemost 79:119-121.

22. Fekih-MrissaN, Mrad M, Klai S, (2013) Methylenetetrahydrofolate reductase (C677T and A1298C) polymorphisms, hyperhomocysteinemia, and ischemic stroke in Tunisian patients. J Stroke Cerebrovasc Dis 22(4):465-469. doi: 10.1016/j.jstrokecerebrovasdis.2013.03.011.

23. Fong CS, Shyu HY, Shieh JC et al (2011) Association of MTHFR, MTR, and MTRR polymorphisms with Parkinson's disease among ethnic Chinese in Taiwan. Clin Chim Acta 412: 332-338. doi: 10.1016/j.cca.2010.11.004

24. Lajin B, Alhaj Sakur A, Michati R et al (2012) Association between MTHFR C677T and A1298C, and MTRR A66G polymorphisms and susceptibility to schizophrenia in a Syrian study cohort. Asian J Psychiatr 5: 144-149. doi: 10.1016/j.ajp.2012.03.002

25. Li WX, Dai SX, Zheng JJ et al (2015) Homocysteine metabolism gene polymorphisms (MTHFR C677T, MTHFR A1298C, MTR A2756G and MTRR A66G) jointly elevate the risk of folate deficiency. Nutrients 7: 6670-6687. doi: 10.3390/nu7085303

26. Li M, Fu B, Dong W (2018) Correlations between plasma homocysteine and MTHFR gene polymorphism and white matter lesions. Folia Neuropathol 56: 301-307. doi: 10.5114/fn.2018.80863

27. Bagley PJ, Selhub J (1998) A common mutation in the methylenetetrahydrofolate reductase gene is associated with an accumulation of formylated tetrahydrofolates in red blood cells. Proc Natl Acad Sci USA 95:13217-13220. doi: 10.1073/pnas.95.22.13217

Page $14 / 19$ 
28. Ueland PM, Hustad S, Schneede J et al (2001) Biological and clinical implications of the MTHFR C677T polymorphism. Trends Pharmacol Sci 22:195-201. doi: 10.1016/s0165-6147(00)01675-8

29. Ramsaransing GSM, Fokkema MR, Teelken A et al (2006) Plasma homocysteine levels in multiple sclerosis. J Neurol Neurosurg Psychiatry 77(2):189-192. doi: 10.1136/jnnp.2005.072199

30. Moghaddasi M, Mamarabadi M, Mohebi N et al (2013) Homocysteine, vitamin B12 and folate levels in Iranian patients with Multiple Sclerosis: a case control study. Clin Neurol Neurosurg 115(9):1802-1805. doi: 10.1016/j.clineuro.2013.05.007

31. Jamroz-Wisniewska A, Beltowski J, Bartosik-Psujek H, et al (2017) Processes of plasma protein N-homocysteinylation in multiple sclerosis. Int J Neurosci 127(8): 709-715. doi: 10.1080/00207454.2016.1241782

32. Kocer B, Engur S, Ak F et al (2009) Serum vitamin B12, folate, and homocysteine levels and their association with clinical and electrophysiological parameters in multiple sclerosis. J Clin Neurosci Mar;16(3):399-403. doi: 10.1016/j.jocn.2008.05.015.

33. Teunissen CE, Killestein J, Kragt JJ et al (2008) Serum homocysteine levels in relation to clinical progression in multiple sclerosis. J. Neurol. Neurosurg. Psychiatr 79 (12): 1349-1353. doi: 10.1136/jnnp.2008.151555

34. Triantafyllou N, Evangelopoulos ME, Kimiskidis VK et al (2008) Increased plasma homocysteine levels in patients with multiple sclerosis and depression. Ann Gen Psychiatry 7:17. doi: 10.1186/1744-859X-7-17. doi: 10.1186/1744-859X-7-17

35. Polman CH, Reingold SC, Banwell B, et al (2011) Diagnostic criteria for multiple sclerosis: 2010 Revisions to the McDonald criteria. Ann Neurol 69(2):292-302. doi: 10.1002/ana.22366

36. Kurtzke JF (1983) Rating neurologic impairment in multiple sclerosis: an expanded disability status scale (EDSS). Neurology 33:1444-1452. doi: 10.1212/wnl.33.11.1444

37. Roxburgh RHSR, Seaman SR, Masterman T et al (2005) Multiple sclerosis severity score: using disability and disease duration to rate disease severity. Neurology 64:1144-1151. https://doi. org/10.1212/01.WNL.0000156155.19270.F8.

38. Koch MW, George S, Wall W et al (2015) Serum NSE level and disability progression in multiple sclerosis. J Neurol Sci Mar 15;350(1-2):46-50. doi: 10.1016/j.jns.2015.02.009.

39. Brazil. Brazilian Institute of Geography and Statistics (IBGE) (2011) Characteristics of the population and households: results of the universe. https://ww2.ibge.gov.br/english/estatistica/populacao/censo2010/caracteristicas_da_populacao/default_caracteristicas_da_populacao.shtm. Accessed 3 Jul 2018.

40. James PA, Oparil S, Carter BL, et al (2014) Evidence-based guideline for the management of high blood pressure in adults: report from the panel members appointed to the Eighth Joint National Committee (JNC 8). JAMA 311(5):507-520. doi: 0.1001/jama.2013.284427

41. American Diabetes Association (2014) Standards of medical care in diabetes-2014. Diabetes Care 37(Suppl 1): S14-80. doi: 10.2337/dc14S014.

42. Benjamini Y, Hochberg Y (1995) Controlling the False Discovery Rate: A Practical and Powerful Approach to Multiple Testing. Journal of the Royal Statistical Society. Series B (Methodological) 57 (1): 289-300. doi.org/10.1111/j.2517-6161.1995.tb02031.x

43. Ringle, C.M., Wende, S. and Becker, J.M. (2015) SmartPLS 3. SmartPLS GmbH, Boenningstedt. http://www.smartpls.com. Acessed 20 Jul 2021

44. Fekih Mrissa N, Mrad M, Klai S et al (2013) Association of methylenetetrahydrofolate reductase A1298C polymorphism but not of C677T with multiple sclerosis in Tunisian patients. Clin Neurol Neurosurg 115(9):1657-1660. doi: 10.1016/j.clineuro.2013.02.025

45. Alatab S, Hossein-nezhad A, Mirzaei K et al (2011) Inflammatory profile, age of onset, and the MTHFR polymorphism in patients with multiple sclerosis. J Mol Neurosci 44(1):6-11. doi: 10.1007/s12031-010-9486-y

46. Klotz L, Farkas M, Bain N et al (2010) The variant methylenetetrahydrofolate reductase c.1298A[C (p. E429A) is associated with multiple sclerosis in a German case-control study. Neurosci Lett 468(3):183-185. doi: 10.1016/j.neulet.2009.10.057

47. Tajouri L, Martin V, Gasparini C et al (2006) Genetic investigation of methylenetetrahydrofolate reductase (MTHFR) and catechol-0-methyl transferase (COMT) in multiple sclerosis. Brain Res Bull 69(3):327-331. doi: 10.1016/j.brainresbull.2006.01.005

48. Cevik B, Yigit S, Karakus N et al (2014) Association of methylenetetrahydrofolate reductase gene C677T polymorphism with multiple sclerosis in Turkish patients. J Investig Med 62(8):980-984. doi: 10.1097/JIM.0000000000000107

49. Naghibalhossaini F, Ehyakonandeh H, Nikseresht A et al (2015) Association Between MTHFR Genetic Variants and Multiple Sclerosis in a Southern Iranian Population. Int J Mol Cell Med (2):87-93

50. Cakina S, Ocak O, Ozkan A et al (2019) Relationship between genetic polymorphisms MTHFR (C677T, A1298C), MTR (A2756G) and MTRR (A66G) genes and multiple sclerosis: a case-control study. Folia Neuropathol 57(1):36-40. doi: 10.5114/fn.2019.83829.

51. Li X, Yuan J, Han J et al (2020) Serum levels of Homocysteine, Vitamin B12 and Folate in Patients with Multiple Sclerosis: an Updated MetaAnalysis. Int J Med Sci 17(6):751-761. doi: 10.7150/ijms.42058

52. Oksenberg JR, Baranzini SE, Barcellos LF et al (2001) Multiple sclerosis: genomic rewards. J Neuroimmunol 113(2):171-184. doi: 0.1016/s0165-5728(00)00444-6.

53. Engbersen A, Franken DG, Boers G et al (1995) Thermolabile 5, 10-methylenetetrahydrofolate reductase as a cause of mild hyperhomocysteinemia. Am J Hum Genet 56(1):142-150

Page 15/19 
54. Jacques PF, Bostom AG, Williams RR et al (1996) Relation between folate status, a common mutation in methylenetetrahydrofolate reductase, and plasma homocysteine concentrations. Circulation 93:7-9. doi: 10.1161/01.cir.93.1.7

55. Chambers JC, Obeid OA, Refsum H et al (2000) Plasma homocysteine concentrations and risk of coronary heart disease in UK Indian Asian and European men. Lancet 355:523-527. doi: 10.1016/S0140-6736(99)93019-2

56. Bailey LB, Duhaney RL, Maneval DR et al (2002) Vitamin B-12 status is inversely associated with plasma homocysteine in young women with C677T and/or A1298C methylenetetrahydrofolate reductase polymorphisms. J Nutr 132:1872-1878. doi: 10.1093/jn/132.7.1872

57. Cong Y, Guo X, Liu X et al (2009) Association of the single nucleotide polymorphisms in the extracellular matrix metalloprotease-9 gene with PACG in southern China. Mol Vis 15:1412-1417

58. Ghazouani L, Abboud N, Mtiraoui N et al (2009) Homocysteine and methylenetetrahydrofolate reductase C677T and A1298C polymorphisms in Tunisian patients with severe coronary artery disease. J Thromb Thrombolysis 27:191-197. doi: 10.1007/s11239-008-0194-1

59. Dardiotis E, Arseniou S, Sokratous M et al (2017) Vitamin B12, folate, and homocysteine levels and multiple sclerosis: a meta-analysis. Mult. Scler. Relat. Disord 17: 190-197. doi: 10.1016/j.msard.2017.08.004

60. Kruman II, Culmsee C, Chan SL et al (2000) Homocysteine elicits a DNA damage response in neurons that promotes apoptosis and hypersensitivity to excitotoxicity. J Neurosci 20(18):6920-6926. doi: 10.1523/JNEUROSCI.20-18-06920.2000

61. Diaz-Arrastia, R (2000) Homocysteine and neurologic disease. Arch. Neurol 57 (10): 1422-1427. doi: 10.1001/archneur.57.10.1422

62. Reynolds E (2006) Vitamin B12, folic acid, and the nervous system. Lancet Neurol 5 (11): 949-960. doi: 10.1016/S1474-4422(06)70598-1

63. Obeid R, McCaddon A, Herrmann W (2007) The role of hyperhomocysteinemia and B-vitamin deficiency in neurological and psychiatric diseases. Clin Chem Lab Med 45(12): 1590-1606. doi: 10.1515/CCLM.2007.356

64. Dubchenko E, Ivanov A, Spirina N, Smirnova N, Melnikov M, Boyko A, Gusev E, Kubatiev A (2020) Hyperhomocysteinemia and Endothelial Dysfunction in Multiple Sclerosis. Brain Sci 10(9):637. doi: 10.3390/brainsci10090637

65. Mattson MP, Shea TB (2003) Folate and homocysteine metabolism in neural plasticity and neurodegenerative disorders. Trends Neurosci 26(3): 137-146. 43. doi: 10.1016/S0166-2236(03)00032-8

66. Kim JK. Mastronardi FG, Wood DD et al (2003) Multiple sclerosis: an important role for post-translational modifications of myelin basic protein in pathogenesis. Mol. Cell Proteom 2 (7): 453-462. doi: 10.1074/mcp.M200050-MCP200

67. Vrethem M, Mattsson E, Hebelka H et al (2003) Increased plasma homocysteine levels without signs of vitamin B12 deficiency in patients with multiple sclerosis assessed by blood and cerebrospinal fluid homocysteine and methylmalonic acid. Mult. Scler 9 (3): 239-245. doi: 10.1191/1352458503ms918oa

68. Sahin S, Aksungar FB, Topkaya AE et al (2007) Increased plasma homocysteine levels in multiple sclerosis. Mult Scler 13(7):945-946. doi: $10.1177 / 1352458506075503$

69. Fahmy EM, Elfayoumy NM, Abdelalim AM, et al (2018) Relation of serum levels of homocysteine, vitamin B12 and folate to cognitive functions in multiple sclerosis patients. Int J Neurosci 128(9): 835-841. doi: 10.1080/00207454.2018.1435538

70. MacFarlane AJ, Greene-Finestone LS, Shi Y (2011) Vitamin B-12 and homocysteine status in a folate-replete population: results from the Canadian Health Measures Survey. Am J Clin Nutr 94(4): 1079-1087. doi: 10.3945/ajcn.111.020230

71. Hilgenbrink AR, Low PS (2005) Folate receptor-mediated drug targeting: from therapeutics to diagnostics. J Pharm Sci 94:2135-2146. doi: 10.1002/jps.20457

72. Turk MJ, Breur GJ, Widmer WR et al (2002) Folate targeted imaging of activated macrophages in rats with adjuvant-induced arthritis. Arthritis Rheum 46:1947-1955. doi: 10.1002/art.10405

73. Elo P, Li XG, Liljenbäck H et al (2021) Efficacy and tolerability of folate-aminopterin therapy in a rat focal model of multiple sclerosis. J Neuroinflammation 18(1):30. doi: 10.1186/s12974-021-02073-7

74. Lynn RC, Poussin M, Kalota A et al (2015) Targeting of folate receptor $\beta$ on acute myeloid leukemia blasts with chimeric antigen receptorexpressing T cells. Blood. 125(22):3466-3476. doi: 10.1182/blood-2014-11-612721

75. Dong Y, Wang L, Lei Y et al (2018) Gene variants in the folate pathway are associated with increased levels of folate receptor autoantibodies. Birth Defects Res. 110(12):973-981. doi: 10.1002/bdr2.1334

76. Undas A, Perla J, Lacinski M et al (2004). Autoantibodies against N-homocysteinylated proteins in humans: implications for atherosclerosis. Stroke 35(6),1299-1304. https://doi.org/10.1161/01.STR.0000128412.59768.6e

77. Undas A, Stïpien E, Glowacki R et al (2006). Folic acid administration and antibodies against homocysteinylated proteins in subjects with hyperhomocysteinemia. Thrombosis and Haemostasis 96(09), 342-347. https://doi.org/10.1160/ th06-04-0228

78. Liu, Z.; Luo, H.; Zhang, L et al (2012) Hyperhomocysteinemia exaggerates adventitial inflammation and angiotensin II-induced abdominal aortic aneurysm in mice. Circ Res 111:1261-1273. doi: 10.1161/CIRCRESAHA.112.270520

79. Álvarez-Sánchez N, Álvarez-Ríos Al, Guerrero JM et al (2020) Homocysteine and C-reactive protein levels are associated with frailty in older Spaniards: The Toledo Study for Healthy Aging. J Gerontol A Biol Sci Med Sci 75(8):1488-1494. doi: 10.1093/gerona/glz168

Page $16 / 19$ 
80. Elsherbiny NM, Sharma I, Kira D et al (2020) Homocysteine Induces Inflammation in Retina and Brain Biomolecules 10(3):393. doi: 10.3390/biom10030393

81. Holven, KB, Holm, T, Aukrust, P et al (2001) Effect of folic acid treatment on endothelium-dependent vasodilation and nitric oxide-derived end products in hyperhomocysteinemic subjects. Am. J. Med 110, 536-542. doi: 10.1016/s0002-9343(01)00696-9

82. Wagner CA, Roqué PJ, Goverman JM (2020) Pathogenic T cell cytokines in multiple sclerosis. J Exp Med 217(1): e20190460. doi: 10.1084/jem.20190460

83. Imitola J, Chitnis T and Khoury SJ (2005) Cytokines in multiple sclerosis: from bench to bedside. Pharmacol Ther 106: 163-177. doi: 10.1016/j.pharmthera.2004.11.007

84. Musabak U, Demirkaya S, Genç G (2011) Serum adiponectin, TNF-a, IL-12p70, and IL-13 levels in multiple sclerosis and the effects of different therapy regimens. Neuroimmunomodulation 18(1):57-66. https://doi.org/10.1159/000317393

85. Mezzaroba L, Simão ANC, Oliveira SR et al (2020) Antioxidant and Anti-inflammatory Diagnostic Biomarkers in Multiple Sclerosis: A Machine Learning Study.Mol Neurobiol 57(5):2167-2178. doi: 10.1007/s12035-019-01856-7

86. Ribeiro CM, Oliveira SR, Alfieri DF et al (2019) Tumor necrosis factor alpha (TNF-a) and its soluble receptors are associated with disability, disability progression and clinical forms of multiple sclerosis. Inflamm Res 68(12):1049-1059. doi: 10.1007/s00011-019-01286-0

87. de Carvalho Jennings Pereira WL, Flauzino T, Alfieri DF et al (2020) Immune-inflammatory, metabolic and hormonal biomarkers are associated with the clinical forms and disability progression in patients with multiple sclerosis: A follow-up study. J Neurol Sci 15;410:116630. doi: 10.1016/j.jns.2019.116630

88. Yokota T, Oritani K, Takahashi I et al (2000) Adiponectin, a new member of the family of soluble defense collagens, negatively regulates the growth of myelomonocytic progenitors and the functions of macrophages. Blood 96(5):1723-1732. doi: 10.1016/j.pharmthera.2004.11.007

89. Wolf AM, Wolf D, Rumpold H (2004) Adiponectin induces the anti-inflammatory cytokines IL-10 and IL-1RA in human leukocytes. Biochem Biophys Res Commun 323(2):630-635. doi: 10.1016/j.bbrc.2004.08.145

90. Kvistad SS, Myhrn SS, Holmøy T et al (2018) Serum levels of leptin and adiponectin are not associated with disease activity or treatment response in multiple sclerosis. J Neuroimmunol 323:73-77. doi: 10.1016/j.jneuroim.2018.07.011

91. Oliveira SR, Simão ANC, Alfieri DF et al (2017) Vitamin D deficiency is associated with disability and disease progression in multiple sclerosis patients independently of oxidative and nitrosative stress. J Neurol 381:213-219. doi: 10.1016/j.jns.2017.07.046

92. Mandia D, Ferraro OE, Nosari G et al (2014) Environmental factors and multiple sclerosis severity: a descriptive study. Int J Environ Res Public Health 11(6):6417-6432. doi: 10.3390/ijerph110606417.

93. Ascherio A, Munger KL, Simon KC (2010) Vitamin D and multiple sclerosis. Lancet Neurol 9(6):599-612. doi: 10.1016/S1474-4422(10)70086-7.

94. Cohen-Lahav M, Shany S, Tobvin D et al (2006) Vitamin D decreases NFkappaB activity by increasing I kappa B alpha levels. Nephrol Dial Transplant 21(4):889-897. doi: 10.1093/ndt/gfi254.

95. Boonstra A, Barrat FJ, Crain C et al (2001) 1alpha,25-Dihydroxyvitamin d3 has a direct effect on naive CD4(+) T cells to enhance the development of Th2 cells. J Immunol 167(9):4974-4980. doi: 10.4049/jimmunol.167.9.4974

96. Rotstein, D.; Montalban, X (2019) Reaching an evidence-based prognosis for personalized treatment of multiple sclerosis. Nat Rev Neurol 15: 287-300. doi: 10.1038/s41582-019-0170-8

97. Seccia R, Romano S, Salvetti M et al (2021) Machine Learning Use for Prognostic Purposes in Multiple Sclerosis. Life (Basel) 11(2):122. doi: 10.3390/life11020122.

\section{Figures}




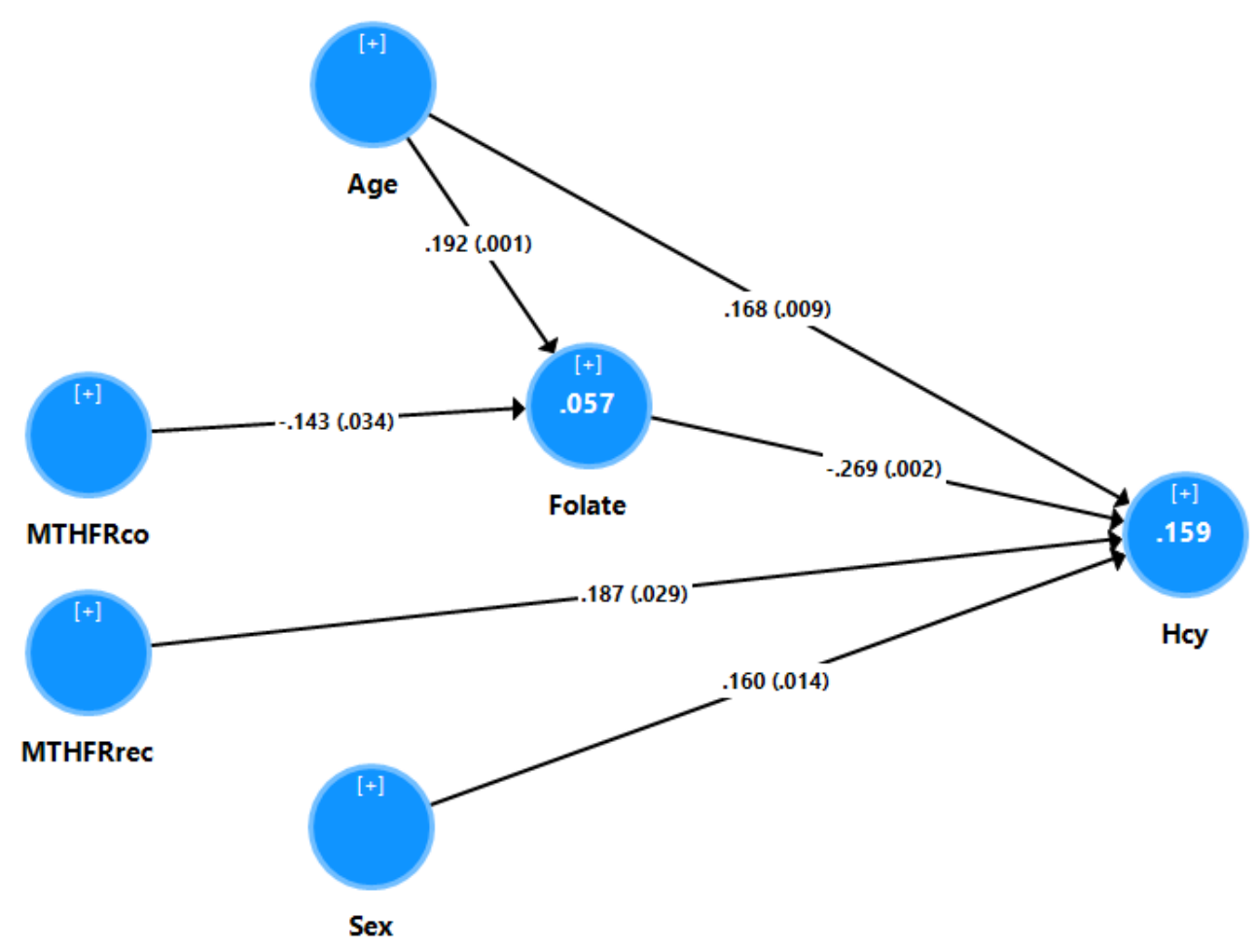

Figure 1

Results of Partial Least Squares (PLS) path analysis performed in healthy controls. This PLS analysis shows the causal relationships between the MTHFR C677T variant (entered as recessive and additive models), age and sex (entered as independent variables) and homocysteine (Hcy) (entered as final dependent variable). Folate was entered as a partial mediator allowing for mediated effects of the genotypes, age and sex on Hcy levels. MTHFRco: additive model ( $C C=-1 ; C T=0 ; T T=+1)$; MTHFRrec: recessive model (CC + CT vs. TT genotypes); Associations are defined as pathways coefficients with p-values. The white figures in the circles indicate the explained variance. 


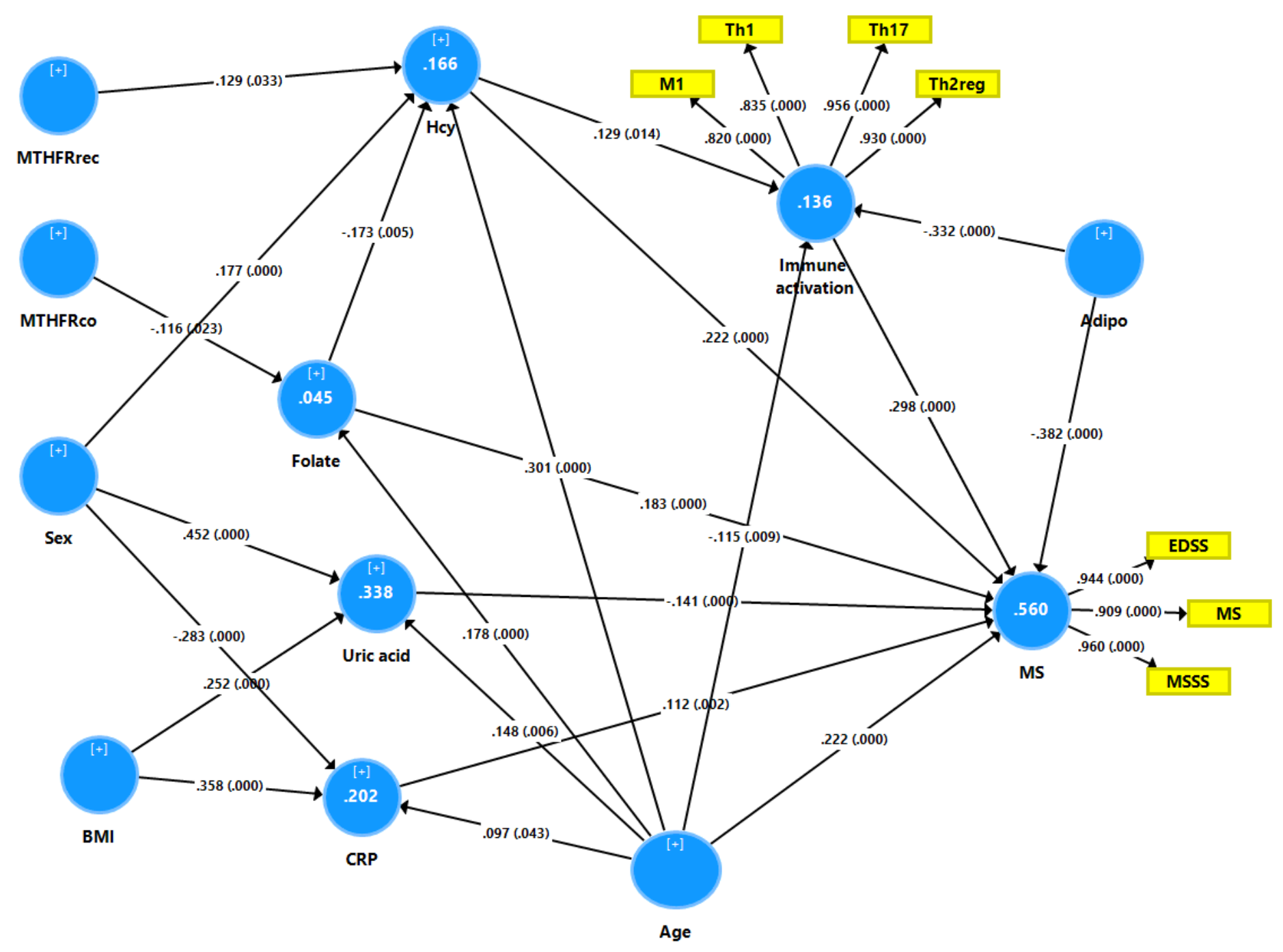

Figure 2

Results of Partial Least Squares (PLS) path analysis performed in all patients with multiple sclerosis (MS) and healthy controls combined. This PLS analysis shows the relationship between MTHFR 677C >T variant, demographic and metabolic data, immune activation index (IAI), homocysteine, folate plasma levels, and MS-EDSS-MSSS [an index of MS and its severity, entered as a latent vector extracted from MS diagnosis, disability (EDSS) and disability progression (MSSS). IAI was entered as a latent vector extracted from macrophage M1, T helper (Th) 1, Th17, and Th2+T regulatory (Treg) cytokine levels. The other variables were entered as single indicators. Associations are defined as pathways coefficients with p-values. The figures in the circles indicate the explained variance. MTHFRco: additive model of the MTHRF $677 \mathrm{C}>\mathrm{T}$ variant $(\mathrm{CC}=-1 ; \mathrm{CT}=0$; TT=1); MTHFRrec: recessive model of the MTHRF 677C>T variant (CC + CT vs. TT genotypes); BMI: body mass index; Hcy: homocysteine levels; CRP: C-reactive protein; MS: multiple sclerosis; EDSS: Expanded Disability Status Score; MSSS: Multiple Sclerosis Severity Score; Adipo:

adiponectin; M1: macrophage M1 cytokines as interleukin (IL)- 6 and tumor necrosis factor (TNF)-a; Th1: T helper 1 cytokines as IL-2 and interferon (IFN)- $ү$;Th17: T helper 17 cytokines as IL-17 and IL-6; Th2reg: T helper 2 and T regulatory cytokines as IL-4 and IL-10. 